\title{
Effects on Strengths of Cement Mortar When Using Incinerator Bottom Ash as Fine Aggregate
}

\author{
Min-Jen Yang, Hong-Yu Wang, Chou-Fu Liang* \\ Department of Civil Engineering, National Pingtung University of Science and Technology, Taiwan \\ Email: ${ }^{\text {Lcf66131@mail.npust.edu.tw }}$
}

Received July 2014

\section{Abstract}

The main purpose of this paper is to study the feasibility of using the Incinerator bottom ash fine aggregate to replace natural fine aggregate in the cement mortar products. The research adopts high cement content mortar to conduct the experiment, in which the weight ratio of cement/aggregate is $1 / 2$. The experiment uses Incinerator bottom ash fine aggregates, which passes through \#16 sieve, and natural sand of the same size as the aggregate, and separates mortar specimens into two main categories based on different $\mathrm{W} / \mathrm{C}$ ratio. Moreover, different proportions of furnace slag and F-class are used to replace a portion of cement so as to explore the influence on strength of Incinerator bottom ash aggregates mortar by adding the two admixtures. The study shows that, based on the 1:2 cement/aggregate weight ratio, Incinerator bottom ash fine aggre-gates mortar, unit weight around $1.8 \mathrm{~g} / \mathrm{cm}^{3}$, is $20 \%$ lighter natural fine aggregate mortar, unit weight around 2.2 $\mathrm{g} / \mathrm{cm}^{3}$. The Incinerator bottom ash fine aggregates mortar can only reach $60 \%-70 \%$ the compressive strength of natural fine aggregates mortar. Direct tensile strength and flexural tensile strength tests are $15 \%$ and $30 \%$ of compressive strength respectively, due to the irregular strength development, which does not follow general concepts, such as low $\mathrm{W} / \mathrm{C}$ ratio and mineral admixtures will not necessarily help in strength development in Incinerator bottom ash fine aggregates mortar.

\section{Keywords}

\section{Incinerator Bottom Ash Aggregrate, Mineral Admixture, Cement Mortar}

\section{Introduction}

Incinerator bottom ash (abbreviated as IBA in the following of this paper) aggregates mainly come from the solid remains of refuse incineration plant, by going through certain leaching and sieving processes. The main purpose of this paper is to study the feasibility of using the IBA fine aggregate to replace natural fine aggregate in the cement mortar products. The research intend to use recycled waste and transform the "waste" into "resources", and put them into construction materials to meet the concepts of "green construction", "environment protection" and "recycling resource” [1]. However, in order to further understand the application of IBA aggregates based cement concrete product, the study also discusses the effects of IBA fine aggregates on the strength

\footnotetext{
${ }^{*}$ Corresponding author.
} 
of cement mortar and the strength variations when using fly ash and blast furnace slag to partially substitute cement [2]. The study hopefully could provide viable direction for future study of using IBA aggregates in cement concrete products.

\section{Research Purpose}

For the time being, in Taiwan, the IBA aggregates are often used in permeable recycled concrete with lean concrete proportions. However, the low strength of permeable concrete mainly comes from low cement contains, which cannot clearly show the impact IBA aggregates on the concrete strength [3] [4]. In permeable concrete the cement weights around 1/8 of aggregate. To eliminate the effect of lean concrete on strength, the research adopts high cement content mortar to conduct the experiment, in which the weight ratio of cement/aggregate is $1 / 2$. The experiment uses IBA fine aggregates, which passes through \#16 sieve, and natural sand of the same size as the aggregate, and separates mortar specimens into two main categories in which each contains 6 groups of specimen, based on different W/C ratio and mineral admixtures portions. The specimens consist of $5 \times 5 \times 5 \mathrm{~cm}$ cubic blocks, Briquet pieces, and $4 \times 4 \times 16 \mathrm{~cm}$ rectangular bars and are used in performing compressive and tensile strength measuring to discuss the basic properties of each group of cement mortar. Moreover, to comply with economic and environmental principles, it adds different proportions of furnace slag and F-class fly ash to replace a portion of cement so as to explore the influence on strength of IBA aggregates concrete by adding the two admixtures [5].

\section{Research Method}

The experiment uses IBA fine aggregates passing through \#16 sieve and natural fine aggregates with same size as the aggregate, and the admixtures are F-type fly ash and blast furnace slag. Adding the two admixtures is expected to increase the workability and strength of the mortar specimens. The experiment is divided into two main groups based on W/C ratio. Each main group contains 6 subgroups in which the specimens consist of different percentage of IBA fine aggregates, fly ash, and furnace slag, so as to verify the effects of the ingredients on the strength of the specimens. The proportions of mortar are as shown, by ratio of weight, in Table 1. The test specimens are mainly divided into 12 groups, wherein the mortars, namely "Control 1" and "Control 2", contain 100\% nature fine aggregate are as the controlled basis, the subgroups, namely group A-J, use only IBA fine aggregates and different portions of fly ash and furnace slag partially replacing cement, so as to explore the strength differences among the groups. The water cement ratio of the specimens are controlled by standard mortar flow test, the mortar flow of each group falls between 100\% - 150\% to insure that no cement paste segregation occurs when casting the specimens.

\section{Results and Discussion}

\subsection{Basic Physical Property Test of Incineration Bottom Ash}

The test results of basic properties testing are shown in Table 2. As being expected, the IBA fine aggregates has a higher water absorption capacity than natural fine aggregate, and its specific gravity and dry-rodded unit weight are also lower than those of natural fine aggregate. For the bottom ash has a faster water absorption rate, the $30 \mathrm{~min}$. absorption rate, which is not a standard test, is mainly used as a reference in process of adding water when mixing the cement mortar containing IBA fine aggregates. That can prevent higher absorption capacity of IBA fine aggregates from affecting the designed water cement ratio during mixing mortar.

\subsection{Result Analysis}

The material ages for each strength test are 7, 28 and 56 days. The tests performed are compressive, direct tensile, and flexural tensile strengths of mortar specimens, which are to get a preliminary understanding of the influence of IBA fine aggregates and mineral admixture on strength of the mortars. The strength test result of each specimen after 7, 28 and 56 days curing is shown in Table 3. In general, material age of 7 days has lower and inconsistent compressive strength due to the incomplete hydration, so the 7-day strength is only taken as reference. Unit weight of each specimen is shown in Table 4. When the aggregate is replaced by IBA fine aggregates, there is obvious difference on the unit weight, due to the lower specific gravity of IBA fine aggregates. 
Table 1. The ratio of Cement Mortar to material by weigh [1]

\begin{tabular}{|c|c|c|c|c|c|c|}
\hline Specimen Group & Water & Cement & Fly Ash & Slag & IBA Fine Aggregates & Nature Sand \\
\hline Control 1 & 1.4 & 2 & --- & --- & --- & 4 \\
\hline Control 2 & 1.36 & 2 & --- & --- & --- & 4 \\
\hline A & 1.4 & 2 & --- & --- & 4 & --- \\
\hline B & 1.36 & 2 & --- & --- & 4 & --- \\
\hline $\mathrm{C}$ & 1.4 & 1.8 & 0.2 & --- & 4 & --- \\
\hline $\mathrm{D}$ & 1.4 & 1.6 & 0.4 & --- & 4 & --- \\
\hline E & 1.36 & 1.8 & 0.2 & --- & 4 & --- \\
\hline $\mathrm{F}$ & 1.36 & 1.6 & 0.4 & --- & 4 & --- \\
\hline G & 1.4 & 1.8 & --- & 0.2 & 4 & --- \\
\hline $\mathrm{H}$ & 1.4 & 1.6 & --- & 0.4 & 4 & --- \\
\hline I & 1.36 & 1.8 & --- & 0.2 & 4 & --- \\
\hline $\mathrm{J}$ & 1.36 & 1.6 & --- & 0.4 & 4 & --- \\
\hline
\end{tabular}

Table 2. The General Aggregate Test of the basic physical properties and the bottom ash properties.

\begin{tabular}{ccccc}
\hline & $\begin{array}{c}\text { Gs (SSD) } \\
\text { Specific Gravity }\end{array}$ & $\begin{array}{c}\text { Absorption Capacity } \\
(\%)\end{array}$ & $\begin{array}{c}\text { Dry-rodded unit weight } \\
\left(\mathrm{kg} / \mathrm{m}^{3}\right)\end{array}$ & $\begin{array}{c}30 \text { min Absorption Rate } \\
(\%)\end{array}$ \\
\hline Natural fine aggregate & 2.68 & 1.8 & 1616 & - \\
IBA fine aggregates & 2.2 & 9.2 & 1125 \\
\hline
\end{tabular}

Table 3. The test result of the intensity of anti-press, anti-pull, and anti-bend.

\begin{tabular}{cccccccccc}
\hline \multirow{2}{*}{\begin{tabular}{c} 
Strength and age \\
\cline { 2 - 10 } Specimen Group
\end{tabular}} & \multicolumn{3}{c}{ Compressive Strength $\left(\mathrm{kg} / \mathrm{cm}^{2}\right)$} & \multicolumn{3}{c}{ Tensile Strength $\left(\mathrm{kg} / \mathrm{cm}^{2}\right)$} & \multicolumn{3}{c}{ Flexural Strength $\left(\mathrm{kg} / \mathrm{cm}^{2}\right)$} \\
\cline { 2 - 10 } Control 1 & 7 & 28 & 56 & 7 & 28 & 56 & 7 & 28 & 56 \\
Control 2 & 292.59 & 256.69 & 384.97 & 31.53 & 31.53 & 40.53 & 58.614 & 67.02 & 77.249 \\
A & 133.87 & 192.38 & 217.66 & 15.71 & 19.79 & 24.46 & 36.713 & 38.82 & 46.827 \\
B & 197.35 & 209.46 & 289.05 & 21.47 & 22.02 & 21.12 & 43.482 & 50.29 & 52.681 \\
C & 160.88 & 257.31 & 274.72 & 19.95 & 21.45 & 24.55 & 40.058 & 46.19 & 55.747 \\
D & 177.1 & 218.94 & 270.57 & 22.67 & 22.92 & 27.84 & 40.536 & 48.5 & 52.083 \\
E & 184.46 & 241.82 & 274.37 & 22.83 & 21.58 & 26.75 & 39.58 & 41.81 & 49.814 \\
F & 149.48 & 193.98 & 276.01 & 16.55 & 20.8 & 23 & 33.567 & 45.47 & 47.464 \\
G & 118.44 & 227.09 & 301.71 & 20.01 & 23.38 & 23 & 35.439 & 46.19 & 50.889 \\
H & 177.92 & 245.2 & 280.67 & 17.45 & 20.39 & 29.68 & 41.571 & 46.27 & 46.986 \\
I & 169.64 & 138.54 & 243.97 & 15.87 & 13.78 & 31.15 & 35.598 & 37.63 & 39.102 \\
J & 165.93 & 236.98 & 268.53 & 20.17 & 26.34 & 31.07 & 42.288 & 43.8 & 46.986 \\
\hline
\end{tabular}

Table 4. Unit weight of test body.

\begin{tabular}{ccccccccccccc}
\hline Group & Control 1 & Control 2 & A & B & C & D & E & F & G & H & I & J \\
\hline $\begin{array}{c}\text { Unit Wt } \\
\left(\mathrm{g} / \mathrm{cm}^{3}\right)\end{array}$ & 2.17 & 2.19 & 1.75 & 1.79 & 1.85 & 1.81 & 1.86 & 1.86 & 1.87 & 1.85 & 1.78 & 1.81 \\
\hline
\end{tabular}

\subsection{Influence of General Mortar and Bottom Ash on Strength}

According to Figure 1, group Control 1 and Control 2, using natural fine aggregate with water cement ratio is 0.7 and 0.68 respectively, have 7 days compressive strengths over $200 \mathrm{~kg} / \mathrm{cm}^{2}$. Mean while, the strength of Control 2 and Group B, due to their lower water cement ratio, get correspondingly higher strength, compare to the 


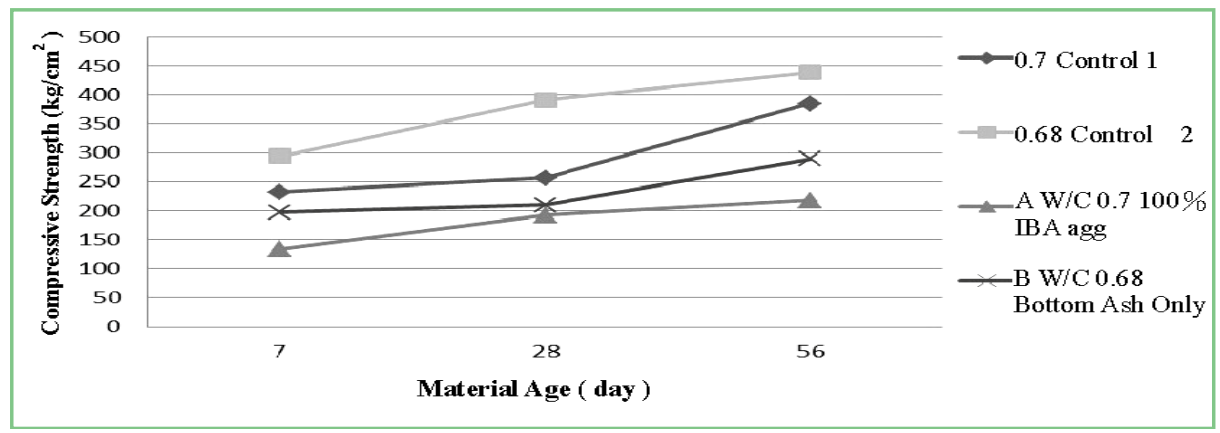

Figure 1. Relation diagram between sand and bottom ash.

$\mathrm{W} / \mathrm{C}=0.7$ in control 1and group A. However, although Group A and B have the same water cement ratio like group Control 1 and Control 2 respectively, due to using IBA fine aggregates only, regardless of the material age, the strengths are around 30\% lower than those of the control group. The strength developments still follow the general theory, i.e. lower water-binder ratio will generate higher strength. However, adding mineral admixtures, fly ash or furnace slag, to replace cement, the strength trends are not as regular.

\subsection{Influence of Mineral Admixture Substituting Cement on Strength}

Table 3 shows the strength of mortar having the same W/C ratio with different mineral admixtures. The groups having $0.7 \mathrm{~W} / \mathrm{C}$ ratio all reach $250 \mathrm{~kg} / \mathrm{cm}^{2}$ average strength of 56 days, expect Group A which has no admixture (IBA fine aggregates only), while the strength of Group G which has $10 \%$ furnace slag reached over $300 \mathrm{~kg} / \mathrm{cm}^{2}$. The strength of groups with mineral admixture is about $100 \mathrm{~kg} / \mathrm{cm}^{2}$ lower than that of the control group, the reduced strength of Group A is twice lower than the group with mineral admixture. When the other mixture proportion is fixed but only alter the water cement ratio, though the difference of W/C ratio is only 0.02 , the strength differences are rather obvious. The strength of group Control 2 at 28 days, Is almost the same as group Control 1 at 56 days age. When the age reaches 56 days, the strength of group Control 2 is higher than $400 \mathrm{~kg} / \mathrm{cm}^{2}$, groups with mineral admixture at 56 days also reach over $250 \mathrm{~kg} / \mathrm{cm}^{2}$; however the strengths of $0.68 \mathrm{~W} / \mathrm{C}$ ratio is slightly lower than those with $0.7 \mathrm{~W} / \mathrm{C}$ ratio.

\subsection{Direct Tensile Test Result}

As shown in Figure 2, compared with cement mortar of control groups, strength of IBA fine aggregate mortar is $30 \%-40 \%$ lower. The test results of other groups with mineral admixtures are the same as the results of compressive strength test. The tensile strength varied slightly of groups with $0.7 \mathrm{~W} / \mathrm{C}$ ratio, Figure 3 shows that the strengths of each group are close to each other and differ no more than $2 \%$, regardless adding furnace slag or fly ash. While the strengths of groups with $0.68 \mathrm{~W} / \mathrm{C}$ ratio have greater difference, as shown in Figure 4, each group differs about $3 \%-5 \%$.

\subsection{Flexural Tensile Test Result}

The differences between mortar in control groups and in IBA fine aggregate mortar are as shown in Figure 5, which shows the same trend as results of direct tensile test. As shown in Figure 6 and Figure 7, the strength developing trend of 0.68 and 0.7 water cement ratio are rather similar, despite $10 \%$ differences, the developing trends are quit flat. All the test results show that when aggregate is substituted by IBA fine aggregates, the lower water cement ratio dose not develop higher strength. Although the Figure 6 and Figure 7 show similar trends, however being compared to control groups, in Figure 7, $0.68 \mathrm{~W} / \mathrm{C}$ ratio groups gain quite low strength, about 40\% lower than group Control 2, while in Figure 6, 0.7 W/C ratio groups is around 20\% weaker than group Control 1.

\section{Conclusion}

The study shows that, based on the 1:2 cement/aggregate weight ratio, Incinerator bottom ash (IBA) fine aggregates mortar, unit weight around $1.8 \mathrm{~g} / \mathrm{cm}^{3}$, is $20 \%$ lighter natural fine aggregate mortar, unit weight around 2.2 


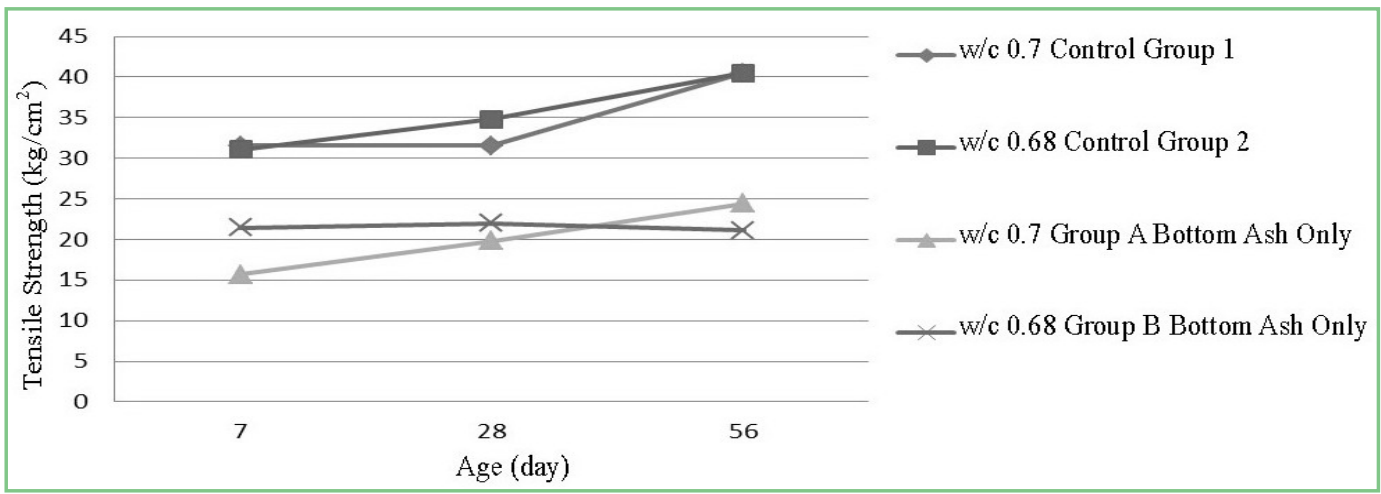

Figure 2. Tensile strength relations among control groupsand bottom ash only groups.

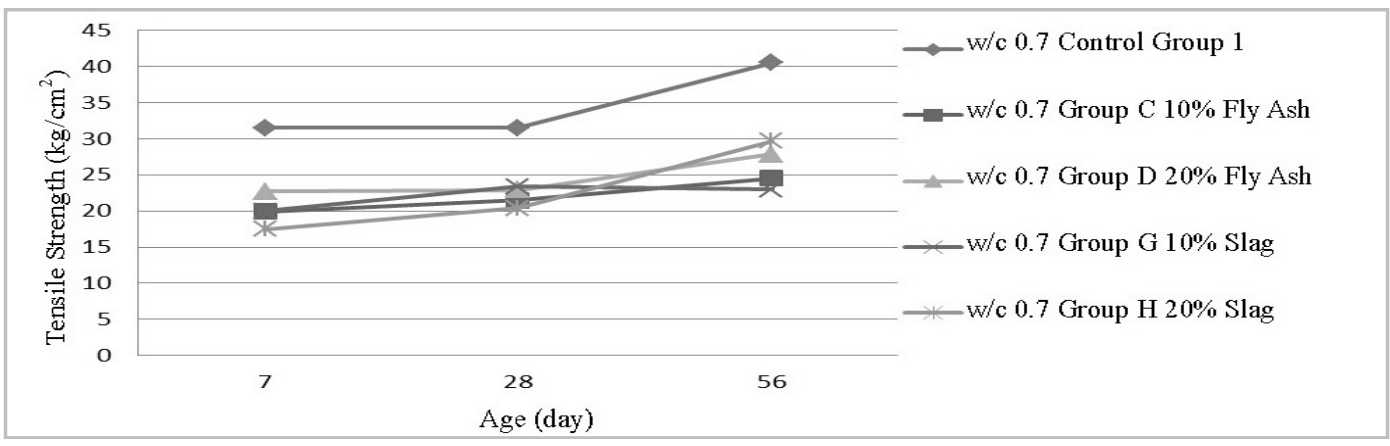

Figure 3. The tensile strength relationship among W/C 0.7 admixture replacement of cement.

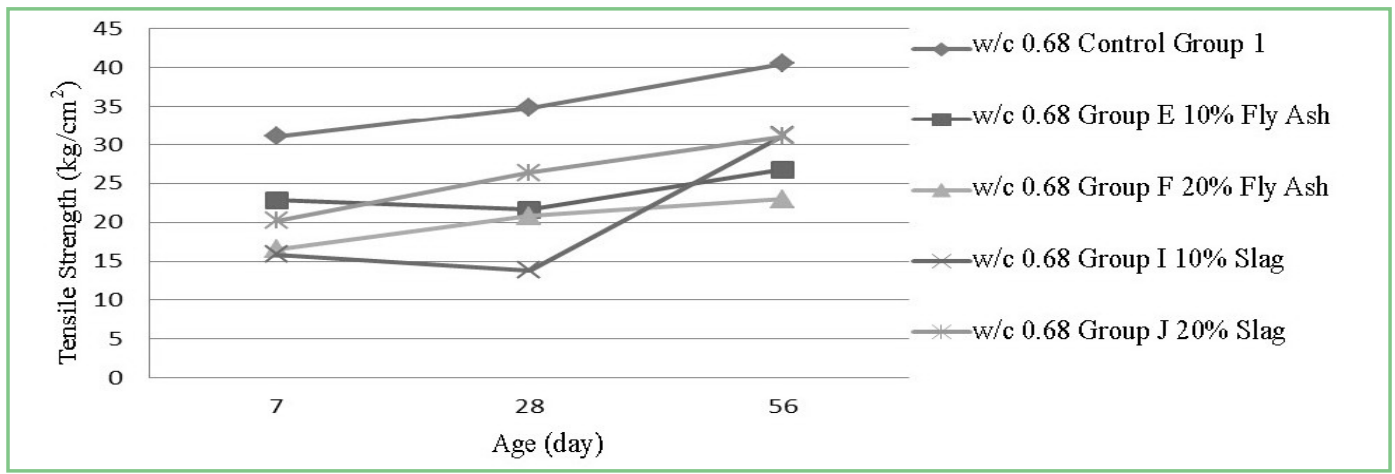

Figure 4. The tensile strength relationship among W/C 0.68 admixture replacement of cement.

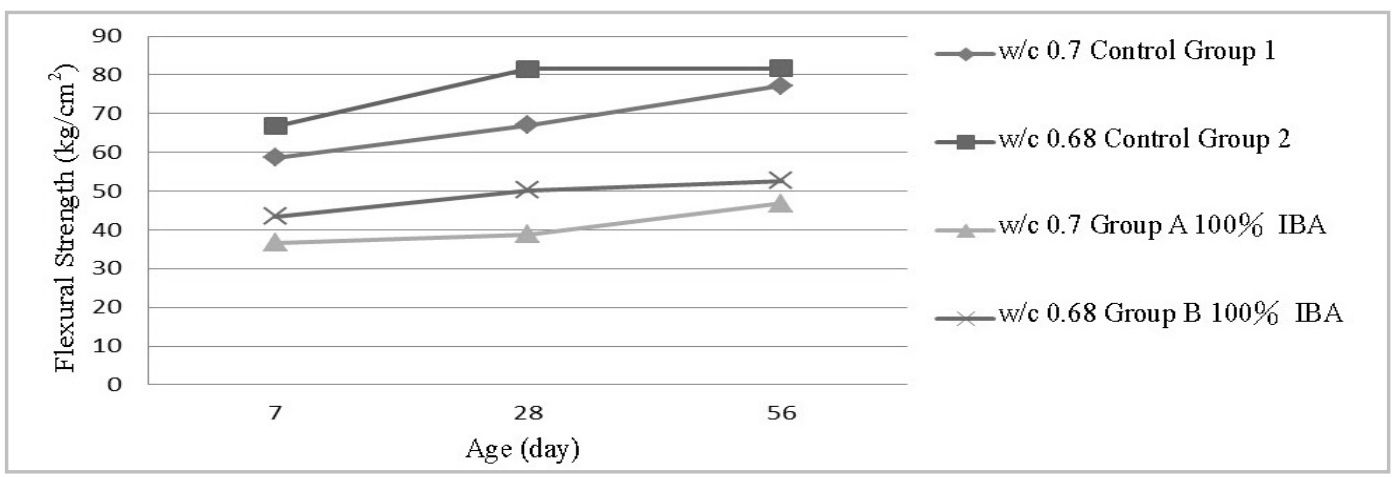

Figure 5. The flexural strength relationship between control group and bottom ash group. 


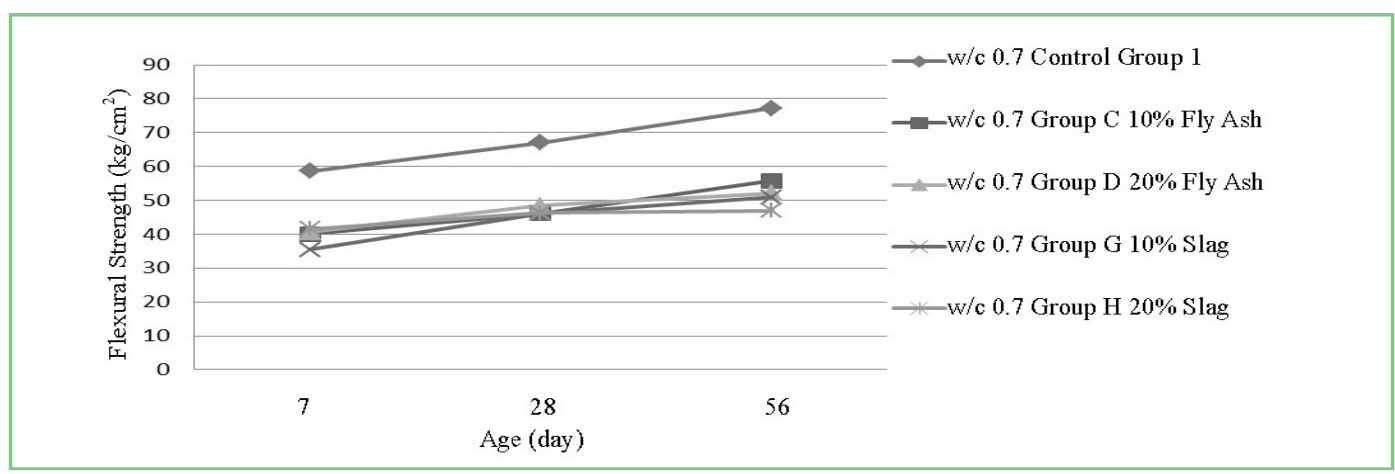

Figure 6. The flexural strength relationship among W/C 0.7 mineral admixture replacement of cement.

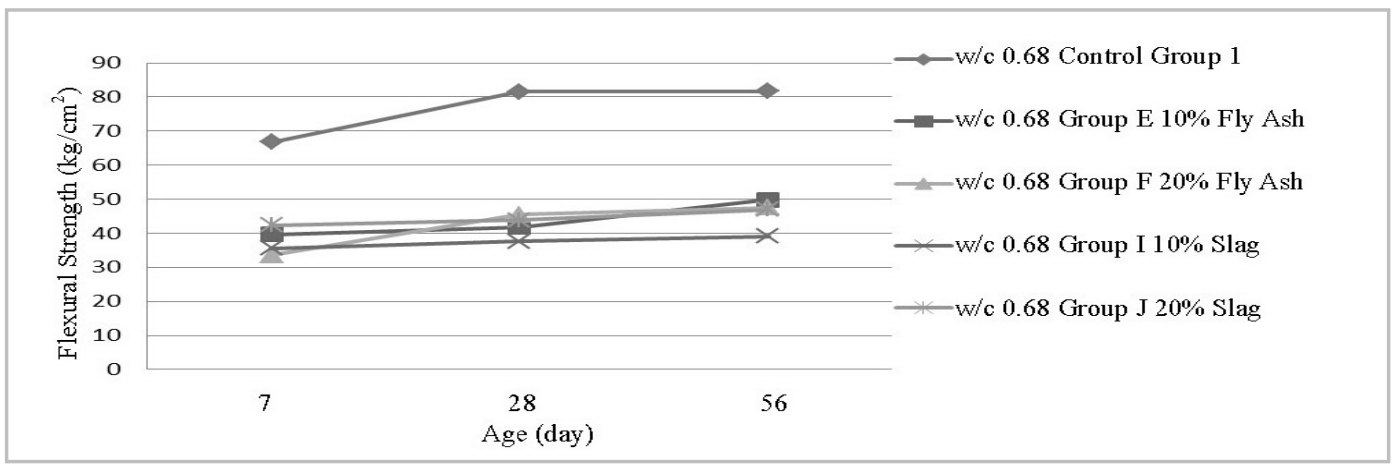

Figure 7. The flexural strength relationship among W/C 0.68 mineral admixture replacement of cement.

$\mathrm{g} / \mathrm{cm}^{3}$. The ratio of unit weight is corresponding to the ratio of specific gravity between IBA fine aggregate, Gs 2.2, and natural fine aggregate, Gs 2.68 . The IBA fine aggregates mortar can only reach $60 \%-70 \%$ the compressive strength of natural fine aggregates mortar. In terms of compressive strength versus unit weight, the lightweight effect of cement mortar or cement related product by using IBA fine aggregates is unable to compensate the strength losses. In IBA fine aggregates mortar, the mineral admixtures fly ash and furnace slag do not help in raising strengths of the mortar specimens, which is contradictory to the general concepts that fly ash and furnace slag will increase the compressive strength at later age of cement concrete. Tensile strengths of IBA fine aggregates mortar obtained from direct tensile strength and flexural tensile strength tests are $15 \%$ and $30 \%$ of compressive strength respectively, there is no obvious difference to the strength percentages obtained from natural fine aggregate mortar. The research suggests that the strength of IBA fine aggregates is the main factor to determine the strengths of the IBA fine aggregates mortar or concrete, due to the irregular strength development, which does not follow general concepts, such as low W/C ratio and mineral admixtures will not necessarily help in strength development in IBA fine aggregates mortar.

\section{References}

[1] Hwang, C.L. (2007) Pozolana Concrete Using Manual. Sinotech Engineering Consultants, Inc., Taipei.

[2] Taiwan Construction Research Institute (2007) Fly Ash and Steel Furnace Slag Application Plan Evaluation Report, China Hi-Ment Corporation Entrust Plan, Plan No: TRC-93003.

[3] Wu, G.Y. (2012) Discussion on Bottom Ash Concrete Building Block Brick Wall. Master Thesis, Civil Engineering Department, NPUST.

[4] Hsieh, Y.-T. (2008) Preliminary Study on Previous Concrete Subject to Freeze Thawing, Fire or Dust Falls. Master Thesis, Construction Engineering Department, CYUT.

[5] Hong, Y.-L. (2009) Study on EAF Slag Concrete Applied on Permeable Surfacing. Master Thesis, Department of Harbor and River Engineering, NTOU. 